\title{
ELEMENTOS TERRAS RARAS NO COMPLEXO GRANITÓIDE ITAQUI (ESTADO DE SÃO PAULO): EVOLUÇÃO E ASPECTOS FÍSICOS DE MAGMAS GRANITÓIDES
}

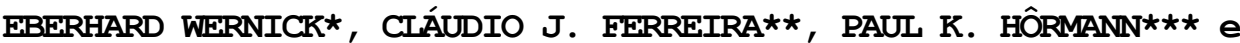

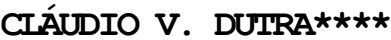

\begin{abstract}
RARE EARTH ELEMENTS IN THE ITAQUI COMPLEX (STATE OF SAO PAULO, BRAZIL): EVOLUTION AND PHYSICAL ASPECTS OF GRANITIC MAGMAS. Petrographic and chemical data from the calc-alkaline multiple and composite Granitoid Itaqui Complex, near the city of São Paulo (State of São Paulo, SE Brazil) are presented and discussed. The complex is built up by 10 magmatic units including different granodiorite, monzogranites and quartz monzonites. Seven of these units belong to two (I, II) successive igneous cycles separated by a phase of more basic intrusions and followed by aplitic dikes. Each cycle, divided into two subcycles (IA, IB, II A, IIB), shows a gradual overall evolution from more basic to more felsic rocks. Also the first unit of subcycle HA is more basic than the corresponding of subcycle IA. In both cycles the total amount of REE decrease with the increase of $\mathrm{SiO}_{2}$, content, but their behavior differ in both cycles. In the first one the $\mathrm{La} / \mathrm{Lu}$ ratios increase continuously, whereas in the other they decrease systematicaly. Such variation is related to major role of zircon fractionation in cycle I and of allanite in cycle II in a combined separation of zircon, allanite, apatite and sphene in both cycles. It is concluded that the viscosity of the granitic magmas was low enough to allow operation of fractional crystallization, probably by convective currents. This conclusion is supported by the presence of enclaves highly enriched in accessory and mafic minerals as well as in REE. None of the REE patterns of both cycles show Eu anomaly with exception of the Suru unit, the latest of the IIB subcycle. This indicates that the REE signatures due to plagioclase fractionation become clear only in highly evolved rocks depleted in accessory mafic minerals.
\end{abstract}

Keywords: Rare-earth elements, calc-alkaline granites, viscosity, magmatic cycles, Itaqui Complex.

RESUMO Apresenta-se e discute-se dados químicos e petrográficos do Complexo Cálcio-Alcalino Itaqui, arredores da cidade de São Paulo, SP. O complexo é múltiplo e composto e sua arquitetura é dada por 10 unidades reunidas em cinco associações que foram agregadas através de quatro fases intrusivas. Petrograficamente, compreendem granodiorito monzogranitos e quartzo monzonitos. Foram definidos dois ciclos magmáticos (I, II), separados por uma fase de diques mais básicos e seguidos da colocação de turmalina-muscovita aplitos. Cada ciclo é dividido em dois subciclos (IA, IB, IIA, IIB) e cada um mostra uma evolução de termos mais básicos para mais ácidos. A unidade inicial do subciclo IIẢ é mais básica que a correspondente do subciclo IA. O conteúdo total em ETR, nos dois ciclos, diminui com o aumento do teor de $\mathrm{SiO}_{2}$, mas seu comportamento varia nos dois ciclos. No primeiro, a razão $\mathrm{La} / \mathrm{Lu}$ aumenta sistematicamente, enquanto, no mais jovem, esta decresce gradualmente. Tal comportamento diferencial é atribuído ao predomínio do \{racionamento de zircão no ciclo I e de allanita no ciclo II, dentro de um fracionamento conjunto nos dois ciclos de zircão, allanita, apatita e titanita. Conclui-se que a viscosidade dos magmas foi suficientemente baixa para permitir a operação de processos de fracionamento, provavelmente por meio de correntes de convecção. Tal conclusão e reforçada pela ocorrência de enclaves enriquecidos em minerais acessórios, fêmicos e em ETR. Nenhum dos padrões de ETR de ambos os ciclos mostra anomalia negativa de Eu, a não ser a Unidade Suru, a mais jovem do subciclo IIB. Isto indica que a assinatura geoquímica, devido ao fracionamento do plagioclásio, só é ressaltada em rochas graníticas evolúdas, empobrecidas em minerais acessórios e máficos.

Palavras-chaves: Elementos terras raras, granitos cálcio-alcalinos, viscosidade, ciclos magmáticos, Complexo Itaqui.

INTRODUCÃ̃o A viscosidade é um parâmetro físico de grande importância no magmatismo granitóide, exercendo papel fundamental no controle do formato e dimensões dos corpos intrusivos e extrusivos, nos processos de desgaseificação de lavas e magmas, bem como na reologia do magma com implicações na preservação de estruturas que retratam a dinâmica magmática, em aspectos texturais e no tipo de colocação final do corpo rochoso. Também é fator decisivo na operação de processos magmáticos evolutivos, caso da cristalização fracionada por ação da gravidade (decantação), por correntes de convecção, filtragem sob compressão etc. (Shaw 1963, 1972, Arzi 1978, Marsh \&
Maxey 1985, Sparks \& Marshal 1986, Marsh 1988, Martin \& Nokes 1989).

A viscosidade de um magma depende de vários fatores, com destaque para a composição química, teor em voláteis, temperatura, pressão e da taxa de fases cristalinas contidas no magma (Arzi 1978). A viscosidade de magmas granitóides é muito variável (Shaw 1965), desde extremamente elevada (que implica em sua movimentação em estado plástico e na presença de feições intrusivas protocataclásticas), até muito baixa, caso de magmas residuais enriquecidos em voláteis. Este é, por exemplo, o caso do Granito Perus (arredores da cidade de São Paulo, SP), um turmalina

\footnotetext{
* Departamento de Petrologia e Metalogenia, Instituto de Geociências e Ciências Exatas, Universidade Estadual Paulista, Caixa Postal 178, CEP 13506900, Rio Claro, SP, Brasil, Fax (0195) 24-9644

** Instituto Geológico, Secretaria do Meio Ambiente, Avenida Miguel Stéfano, 3900, CEP 04301-903, São Paulo, SP, Brasil, Fax (011) $276-8572$

*** Mineralogisch-Petrographisches Institui der Universitat, Ludewig-Meyn Strasse 10, W - 2300 Kiel l, Alemanha

**** GEOSOL, Rua São Vicente, 255, Bairro Olhos D'Agua, CEP 30330-500, Belo Horizonte, MG, FAX (031) 288-1140
} 
granito caracterizado por intensa e persistente estrutura rítmica, na qual cada um dos inúmeros leitos superpostos (com espessura centimétrica e decimétrica) é caracterizado por um sistemático decréscimo no teor de turmalina da base para o topo (Hasui 1963, Wernick 1983).

Complexos granitóides com ampla variação composicional são, em última análise, o resultado final da superposição de numerosos processos aqui arbitrariamente reunidos em quatro etapas: 1. gênese magmática; 2. maturação magmática; 3. movimentação magmática; e 4. etapa principal de cristalização.

A etapa de gênese magmática envolve a geração de magmas que pode dar-se por vários processos, tais como fusão parcial progressiva num sistema fechado (batch melting), fusão parcial progressiva num sistema aberto (fusão progressiva fracionada), mistura magmática etc.

A etapa de maturação magmática envolve os processos de fracionamento do magma (supostamente homogéneo) gerado na etapa anterior, em estado dominantemente líquido e do qual resulta um zoneamento composicional no reservatório magmático. Entre os processos mais ou menos efetivos que atuam nesta etapa, vale mencionar o desenvolvimento de camadas de múltipla difusão (Hildreth 1981, Spera et al 1982, Hildreth et al. 1984, Martin et al 1987), o efeito Soret (Walker \& DeLong 1982), a transferência de material pela ação da fase fluida percolando o magma, o aporte de novos impulsos magmáticos mais ácidos ou básicos que o magma pré-existente (Sparks et al 1984, Campbell \& Turner 1986), a fusão parcial das rochas sobrejacentes ao topo da câmara magmática (Oxburgh \& McRae 1984) etc.

Na etapa de movimentação magmática, a câmara pode ser esvaziada gradualmente pela drenagem, tanto simultânea quanto sucessiva, de níveis magmáticos de composições distintas, dominando o primeiro caso em câmaras rasas (Bailey et al 1976, Hildreth 1981) e o segundo em intrusões mais profundas (Zorpi et al 1989, Jackson \& Talbot 1989). Este caso é atestado, em complexos intrusivos cálcio-alcalinos maiores, por seu caráter polidiapírico, por uma seqüenciação magmática na qual os sucessivos impulsos magmáticos são cada vez mais ácidos e por frequentes feições de commingling entre magmas ácidos e básicos (Zorpi et al 1989, Castro et al 1991, Poli \& Tommasini 1991).

A etapa principal de cristalização envolve a consolidação da maior parte do magma. Na medida em que operar esta etapa com maior intensidade, irá ocorrer o desenvolvimento de um "véu" que mascara em maior ou menor grau os processos que atuaram nas etapas anteriores.

Face ao exposto, os processos genéticos de magmas granitóides só podem ser claramente definidos (no que se refere aos dados geológicos, petrográficos e químicos), se na etapa principal de consolidação magmática a cristalização fracionada não tiver operado com um alto grau de eficiência (o que depende em boa parte da viscosidade do magma) e se durante as etapas de maturação e movimentação magmática não tiverem ocorrido modificações substanciais na composição do magma formado na etapa de gênese. Por isso, é de fundamental importância que num complexo granitóide de ampla variação composicional seja caracterizada, inicialmente, a atuação ou não do processo de fracionamento magmático, antes da tentativa de uma abordagem genética (Reid et al 1983, Chappel et al 1987, Wall et al 1987, Ague \& Brimhall 1988, Leake 1990). Esta é a finalidade deste trabalho, utilizando-se como objeto de investigação o Complexo Granitóide Itaqui dos arredores da cidade de São Paulo, SP, e empregando como método de trabalho elementos terras raras.

ELEMENTOS TERRAS RARAS EM ROCHAS GRANíTICAS Gromet \& Silver (1983) e Budzinski \&
Tischendorf (1989), entre outros, mostraram que em rochas graníticas, tanto do tipo I quanto $\mathrm{S}$, a quase totalidade dos ETR acham-se concentrados nos minerais acessórios, principalmente allanita, xenotima, monazita e titanita e, em menores quantidades, no zircão e na apatita.

Como estes minerais são em sua maioria de formação precoce, num processo de cristalização fracionada, o conteúdo total de ETR deve decrescer sistematicamente, quando relacionado com diferentes índices de evolução magmática. Os ETR também devem mostrar correlação direta com os elementos principais nos minerais acessórios considerados ( $\mathrm{P}$ na apatita, Ti na titanita, $\mathrm{Zr}$ no zircão, $\mathrm{Y}$ na allanita, Ce na monazita, $\mathrm{Y}+\mathrm{P}$ na xenotima), desde que presentes nas rochas investigadas. Como os ETR também ocorrem em menores quantidades nos minerais fêmicos de granitóides (biotita e hornblenda), a sua somatória também deve apresentar correlação positiva com o índice de coloração. Todas estas correlações exigem também boa concordância entre dados químicos e modais nas rochas investigadas, principalmente nos minerais acessórios.

A constatação destas correlações num complexo granitóide de ampla variação composicional indica, então, a operação do processo de cristalização fracionada e assinala que a viscosidade do magma no início do fracionamento foi de tal ordem que permitiu a separação dos minerais de cristalização precoce do líquido coexistente por um ou mais dos processos previamente mencionados.

Petrograficamente, tal fato deve refletir-se na ocorrência, em corpos granitóides de ampla área de exposição, de enclaves enriquecidos em minerais máficos e acessórios com as mesmas características petrográficas gerais dos minerais presentes nas porções mais básicas do corpo magmático considerado (enclaves cognatos).

O COMPLEXO GRANITÓIDE ITAQUI O Complexo Granitóide Itaqui (Ferreira 1991), situado nos subúrbios da cidade de São Paulo, possui forma de peixe (com a "cabeça" a oeste), comprimento de $24 \mathrm{~km}$, largura máxima de $8 \mathrm{~km}$, área aproximada de $120 \mathrm{~km}^{2}$ e direção geral WNW-ESE. Seus contatos W, NW e N são intrusivos em relação aos metamorfitos de baixo grau do Grupo São Roque. Parte de seu contato NE é dado pela Zona de CisaIhamento Vila Menk e sua porção S é limitada pela zona de Cisalhamento Taxaquara, pela qual faz contato com Complexo Granitóide Itapevi (Fig. 1).

A arquitetura do complexo (Fig. 1) compreende as seguintes unidades ígneas, segundo sua sequência temporal de colocação: 1. Granodiorito Barueri (BA); 2. Monzogranito Pedreira Cantareira (PC); 3. diques do Monzogranito Torre (TO); 4. diques máficos de quartzo monzonitos, tanto porfiríticos (DMP) quanto equigranulares (DME) (Wernick \& Ferreira 1987); 5. diques do Quartzo Monzonito Cruz Preta (CP); 6. Monzogranito Aldeia da Serra (AS); 7. Monzogranito Mutinga (MU); 8. diques do Monzogranito Suru (SU); e 9. diques de muscovita-turmalina monzogranitos (APL).

Dados texturais e mineralógicos qualitativos e quantitativos destas unidades constam da tabela 1; e dados modais na figura 2. Todas as unidades caracterizam-se por cores cinza-escuras e esbranquiçadas, com exceção de amostras situadas próximas às zonas de falha e de cisalhamento, quando adquirem cores rosadas ou vermelhas acastanhadas (cor de carne).

Dados petrográficos (Ferreira 1991, Ferreira \& Wernick 1991), químicos (Wernick et al. 1991, 1993) e de tipologia de zircão (Ferreira et al 1992) classificam o Complexo Itaqui como cálcio-alcalino de baixa temperatura.

A arquitetura do Complexo Itaqui resulta de quatro fases principais de acresção magmática (Fig. 1) colocadas em níveis sucessivamente mais rasos e envolvendo magmas 

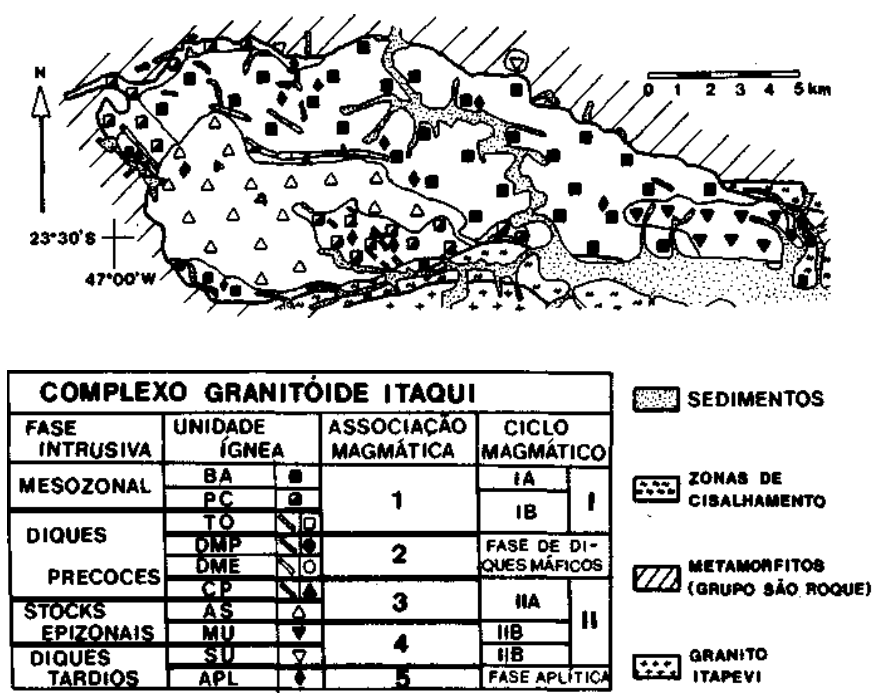

figura 1 - Geologia, unidades ígneas, associações e ciclos magmáticos do Complexo Granitóide Itaqui, SP. Modificado de ferreira \& Wernick (1989), ferreira (1991) e Wernick \& ferreira (1991). Convenções: BA . Granodiorito Barueri; PC. Monzogranito Pedreira Cantareira; TO. Monzogranito Torre; DMP. Dique de quartzo monzonito máfico porfirítico; DME. dique de quartzo monzonito máfico eqüigranular; CP. Quartzo Monzonito Cruz Preta; AS. Monzogranito Aldeia da Serra; MU. Monzogranito Mutinga; $\boldsymbol{S U}$. Monzogranito Suru; e APL. aplitos

Figure 1 - Geology, igneous units and magmatic cycles of Itaqui Granitoid Complex, SP. After Ferreira \& Wernick (1989), Ferreira (1991) and Wernick \& Ferreira (1991). Key: BA. Barueri Granodiorite; PC. Pedreira Cantareira Monzogranite ; TO. Torre Monzogranite ; DMP. quartz monzonite mafic porphiritic dike; DME. quartz monzonite mafic even-grained dike; CP. Cruz Preta Quartz Monzonite; AS. Aldeia da Serra Monzogranite; MU. Mutinga Monzogranite; SU. Suru Monzogranite; and APL. aplite

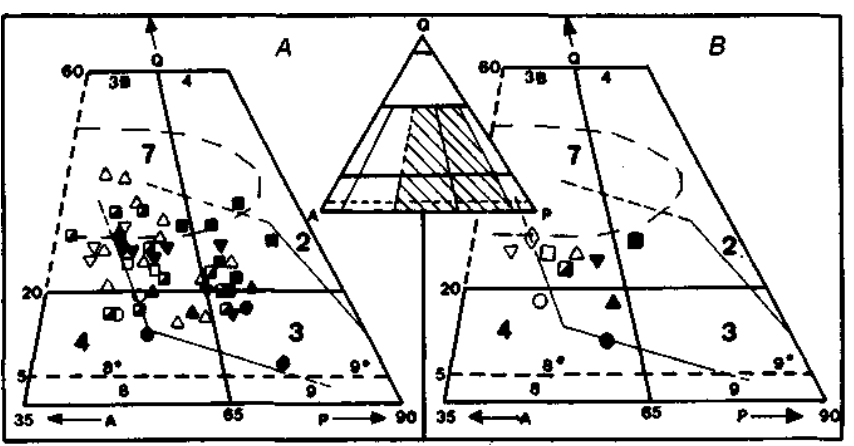

figura 2 - Classificação modal no diagrama QAP (A. valores de amostras individuais; $\boldsymbol{B}$. valores médios) das unidades ígneas do Complexo Granitóide Itaqui. Símbolos segundo a figura 1. Segundo ferreira (1991) e ferreira \& Wernick (1991)

Figure 2- Modal QAPclassification of igneous units of the Itaqui Complex. A. all data; B. averages. Key as figure 1. After Ferreira (1991) and Ferreira \& Wernick (1991)

(com exceção dos aplitos finais), cada vez mais quentes (Ferreira et al 1992). Estas fases foram caracterizadas por Wernick \& Ferreira (1991), em bases geológicas e estruturais:

- uma fase de intrusão de massas mesozonais dadas pelas Unidades Barueri e Pedreira Cantareira;

- uma fase de intrusão de espessos diques precoces que reúne as Unidades DMP e DME (diques máficos porfirítico e equigranular), Torre e Cruz Preta.

- uma fase de intrusão de stocks epizonais englobando as Unidades Mutinga e Aldeia da Serra;

- uma fase de intrusão de diques tardios, representados pela colocação da Unidade Suru, um fragmento de um dique anelar e dos aplitos.

Sob aspecto petrográfico, as unidades magmáticas do Complexo Itaqui são reunidas em cinco associações magmáticas (Wernick e Ferreira, 1991):

Associação 1 - Unidades Barueri, Pedreira Cantareira e Torre;

Associação 2 - diques máficos;

Associação 3 - Unidades Cruz Preta e Aldeia da Serra;

Associação 4 - Unidades Mutinga e Suru;

Associação 5 - aplitos com turmalina e muscovita.

Verifica-se, assim, que as associações magmáticas transgridem, em parte, os limites temporais das quatro fases intrusivas previamente delineadas, o que revela uma defasagem temporal entre os fenômenos tectônicos e as mudanças nas características químicas do magmatismo (Fig. 1). Fenômeno semelhante foi constatado por Artur et al (1991) para o Complexo Granitóide Socorro (SP/MG).

Finalmente, nesta abordagem, é de importância ressaltar:

1. A Unidade BA tem a relação hornblenda/biotita mais alta do complexo, excetuando-se os diques máficos. Esta relacão é mais baixa na Unidade PC e nas Unidades TO, CP, AS, MU e SU; o único mineral máfico presente é a biotita.

2. A presença na Unidade Barueri, de enclaves e coágulos minerais enriquecidos em hornblenda, biotita e minerais acessórios com as mesmas características microscópicas dos minerais equivalentes presentes nas rochas encaixantes. Foram designados por Ferreira (1991) de enclaves cognatos. 3. A frequência dos megacristais de microclina decresce segundo a Sequência BA, PC e TO, o mesmo observando-se para as Unidades CP e AS. A Unidade MU apresenta raros megacristais e a Unidade SU é equigranular (Tab. 1).

4. O zircão das diferentes unidades magmáticas mostra, ao lado de diferentes morfologias, também transparência e modo de ocorrência variável. $O$ zircão apresenta-se tanto sob forma de cristais isolados, quanto constituindo pequenas inclusões nos minerais máficos, o que dificulta a sua exata quantificação modal. Por isso, em algumas unidades, não existe correspondência entre o teor de zircão modal (Tab. 1) e o teor em $\mathrm{Zr}$ (Tab. 2). Além disso, os cristais podem apresentar-se tanto límpidos quanto sujos, escuros, fruto de uma metamictização variável que indica teores diferenciais de elementos radioativos (e por extensão de ETR) nos zircões das diferentes unidades (Ferreira et al. 1992).

5. A apatita apresenta variação na sua morfologia, constituindo ora espessos cristais prismáticos, ora cristais aciculares.

6. A allanita exibe variações nas dimensões e na coloração, ocorrendo ora como cristais maiores ora menores e com tonalidades de cores variáveis, sugerindo alguma variação composicional. $\mathrm{O}$ mesmo fenômeno observa-se também na titanita (Ferreira 1991).

7. Baseado em várias feições petrográficas (tipo de zoneamento do plagioclásio, coexistência de apatitas arredondadas e com formas de agulha, texturas de synneusis, grãos de quartzo manteados por biotita etc) e geológicos (commingling local), Ferreira (1991) propôs para o Granitóide Itaqui uma origem por mistura magmática, sem entre- 
Tabela 1 - Dados texturais e mineralógicos das unidades ígneas do Complexo Itaqui. Convenções: tr - traços; **** - muito frequentes; *** -frequentes; ** - pouco frequentes; * - raros. Modificado de Ferreira (1991) e Ferreira \& Wernick (1991) Table 1 - Mineralogical and textural data for the igneous units of Itaqui Complex. Key:tr- trace; *** - very frequent; *** - frequent; ** - unusual; * - rare. After Ferreira (1991) and Ferreira \& Wernick (1991)

\begin{tabular}{|c|c|c|c|c|c|c|c|c|c|c|}
\hline \multirow{2}{*}{\multicolumn{2}{|c|}{$\begin{array}{l}\text { Unidade } \\
\text { Ignea }\end{array}$}} & \multirow{2}{*}{\multicolumn{2}{|c|}{$\begin{array}{c}\text { Textura } \\
\text { Característica }\end{array}$}} & \multicolumn{3}{|c|}{ Megacristais de FK } & \multirow{2}{*}{\multicolumn{2}{|c|}{$\begin{array}{l}\text { Minerais Máficos } \\
\text { Característicos }\end{array}$}} & \multirow{2}{*}{\multicolumn{2}{|c|}{$\begin{array}{l}\text { Frequiência } \\
\text { de Aplitos }\end{array}$}} \\
\hline & & & & $\%$ & \multicolumn{2}{|c|}{ Dimensẵo Média } & & & & \\
\hline \multicolumn{2}{|l|}{ Barueri } & \multirow{2}{*}{\multicolumn{2}{|c|}{ Porfiróide }} & 12 & \multicolumn{2}{|c|}{$2,5 \mathrm{~cm}$} & \multirow{2}{*}{\multicolumn{2}{|c|}{$\begin{array}{c}\text { Biotita e } \\
\text { hornblenda }\end{array}$}} & \multicolumn{2}{|c|}{ Alta } \\
\hline \multicolumn{2}{|c|}{$\begin{array}{l}\text { Pedreira } \\
\text { Cantareira }\end{array}$} & & & 3 & \multicolumn{2}{|c|}{$3 \mathrm{~cm}$} & & & \multicolumn{2}{|c|}{ Média } \\
\hline \multicolumn{2}{|l|}{ Torte } & \multicolumn{2}{|l|}{ Eqüigranular } & \multicolumn{3}{|c|}{-} & \multicolumn{2}{|c|}{ Biotita } & & \\
\hline DMP & & \multicolumn{2}{|l|}{ Porfirítica } & $0-3$ & \multicolumn{2}{|c|}{$2,5 \mathrm{~cm}$} & \multicolumn{2}{|c|}{ Biotita e hornblenda } & \multirow{2}{*}{\multicolumn{2}{|c|}{ Média }} \\
\hline DME & & \multicolumn{2}{|l|}{ Eqüigranular } & \multicolumn{3}{|c|}{-} & \multicolumn{2}{|c|}{ Biotita e hornblenda } & & \\
\hline Cruz Pret & & \multicolumn{2}{|l|}{ Porfirítica } & 13 & 1 & & & & & \\
\hline $\begin{array}{l}\text { Aldeia da } \\
\text { Serra }\end{array}$ & & $\begin{array}{c}\text { Ineqüigranula } \\
\text { serial a }\end{array}$ & & 3 & 1,5 & & & & Mui & aixa \\
\hline Mutinga & & porfirítica & & Ir & 1,5 & & & & & \\
\hline Suru & & Eqüigranular & & & & & & & & \\
\hline Aplitos & & Aplítica & & & - & & Tum & ina & & \\
\hline Unidade & Barueri & $\begin{array}{l}\text { Pedreira } \\
\text { Cantareira }\end{array}$ & Torre & DMP & DME & $\begin{array}{l}\text { Cruz } \\
\text { Preta }\end{array}$ & Mutinga & $\begin{array}{l}\text { Aldeia } \\
\text { da } \\
\text { Serra }\end{array}$ & Suru & Aplitos \\
\hline Plagioclásio & 41 & 40 & 37 & 35 & 33 & 45 & 43 & 37 & 32 & 33 \\
\hline Feldspato-K & 17 & 32 & 33 & 22 & 33 & 26 & 27 & 28 & 39 & 34 \\
\hline Quartzo & 24 & 22 & 24 & 7 & 14 & 16 & 23 & 24 & 27 & 29 \\
\hline Biotita & 13 & 6 & 4 & 25 & 15 & 11 & 7 & 9 & 2 & - \\
\hline Hornblenda & 3 & 0,4 & - & 4 & 0,5 & - & - & - & - & - \\
\hline Titanita & 1 & 0,2 & 1 & 4 & 3 & 1 & 0,2 & 1 & * & - \\
\hline Opacos & 0,5 & 0,3 & 0,8 & 2 & 1,5 & 1 & * & 0,5 & * & $*$ \\
\hline Apatita & 0,5 & 0,1 & 0,2 & 1 & 0,3 & 0,5 & * & 0,3 & * & $*$ \\
\hline Allanita & $* * * *$ & $* *$ & ** & - & $* *$ & $* *$ & $* * *$ & $* * * *$ & $*$ & $*$ \\
\hline Zircão & $* *$ & $* *$ & $*$ & * & * & $*$ & ** & $*$ & * & - \\
\hline Epídoto & $* *$ & $* *$ & - & ** & ** & $* *$ & $* *$ & $*$ & - & - \\
\hline Muscovita & - & - & - & - & - & - & - & - & - & 4 \\
\hline Turmalina & - & - & - & - & - & - & - & - & - & $* *$ \\
\hline Rutilo & - & - & - & - & - & - & - & - & - & - \\
\hline
\end{tabular}

tanto poder precisar de modo claro a que etapa evolutiva do complexo este processo estaria vinculado: à genética, de maturação, à de movimentação ou à fase de colocação dos magmas mais básicos sinintrusivos que separa temporalmente as Unidades BA, PC e TO das Unidades CP, AS, MU, SU e APL.

DADOS QUÍMICOS $\mathrm{Na}$ tabela 2, constam análises químicas de elementos maiores, menores, traços e ETR referentes às rochas do Complexo Itaqui e, na tabela 3 , a média de alguns elementos maiores, traços e ETR, ao lado de algumas razões médias entre os parâmetros mencionados. As 26 análises de elementos maiores, menores e traços apresentadas foram executadas no Laboratório de Geoquímica do Instituto de Mineralogia e Petrografia da Universidade de Kiel (Alemanha). Das análises de ETR, 16 foram executadas no referido laboratório e 10 na GEOSOL. Duplicatas de amostras realizadas simultaneamente nos dois laboratórios revelaram excelente concordância nos resultados de ETR, sempre obtidos via ICP. 
Os dados listados nas tabelas 2 e 3 foram representados nos seguintes diagramas:

- variação composicional dos elementos maiores e menores de cada unidade magmática (Fig. 3);

- soma dos ETR (valores normalizados por condrito em ppm) versus $\mathrm{SiO}_{2}$, soma dos fềmicos normativos, $\mathrm{Y}, \mathrm{Ti}, \mathrm{P}, \mathrm{Zr}$ e a soma de $\mathrm{Ti}+\mathrm{P}+\mathrm{Zr}+\mathrm{Y}$ (Fig. 4);

- padrões de ETR normalizados por condrito das unidades dos subciclos IA, IB, IIA, IIB, do enclave cognato, dos diques máfícos e aplitos (Fig. 5);

- valores médios dos teores de Ti, $\mathrm{P}, \mathrm{Zr}, \mathrm{Y}$ e $(\mathrm{Ti}+\mathrm{P}+\mathrm{Zr}+\mathrm{Y})$ de cada unidade versus os valores normalizados de ETRL ( $\mathrm{La}+\mathrm{Ce})$, Eu e ETRP (Yb + Lu) (Fig. 6).
DISCUSSÃO DOS RESULTADOS A integração das figuras 3 a 6 com os dados das tabelas 1 a 3 permite as seguintes constatações:

1. A existência de dois ciclos magmáticos principais (I e II), separados por uma fase de diques máficos (DMP e DME) e seguidos da colocação dos aplitos (Fig. 3). Maiores detalhes em Wernick et al. (1993).

2. O ciclo I, reunindo as Unidades BA, PC e TO, pode ser subdividido em dois subciclos: IA (correspondente à unidade $\mathrm{BA}$ ) e IB (reunindo as unidades $\mathrm{PC}$ e TO). O limite entre os subciclos baseia-se em vários óxidos com destaque para o $\mathrm{K}_{2} \mathrm{O}$.

3. O ciclo II, que reúne as Unidades $\mathrm{CP}, \mathrm{AS}, \mathrm{MU}$ e SU,

Tabela 2 - Elementos maiores, menores (em \% de peso), traços e ETR (em ppm) para 26 amostras do Complexo Itaqui Table 2- Major, minor (weight \%) and trace elements and REE (in ppm) for 26 samples of the Itaqui Complex

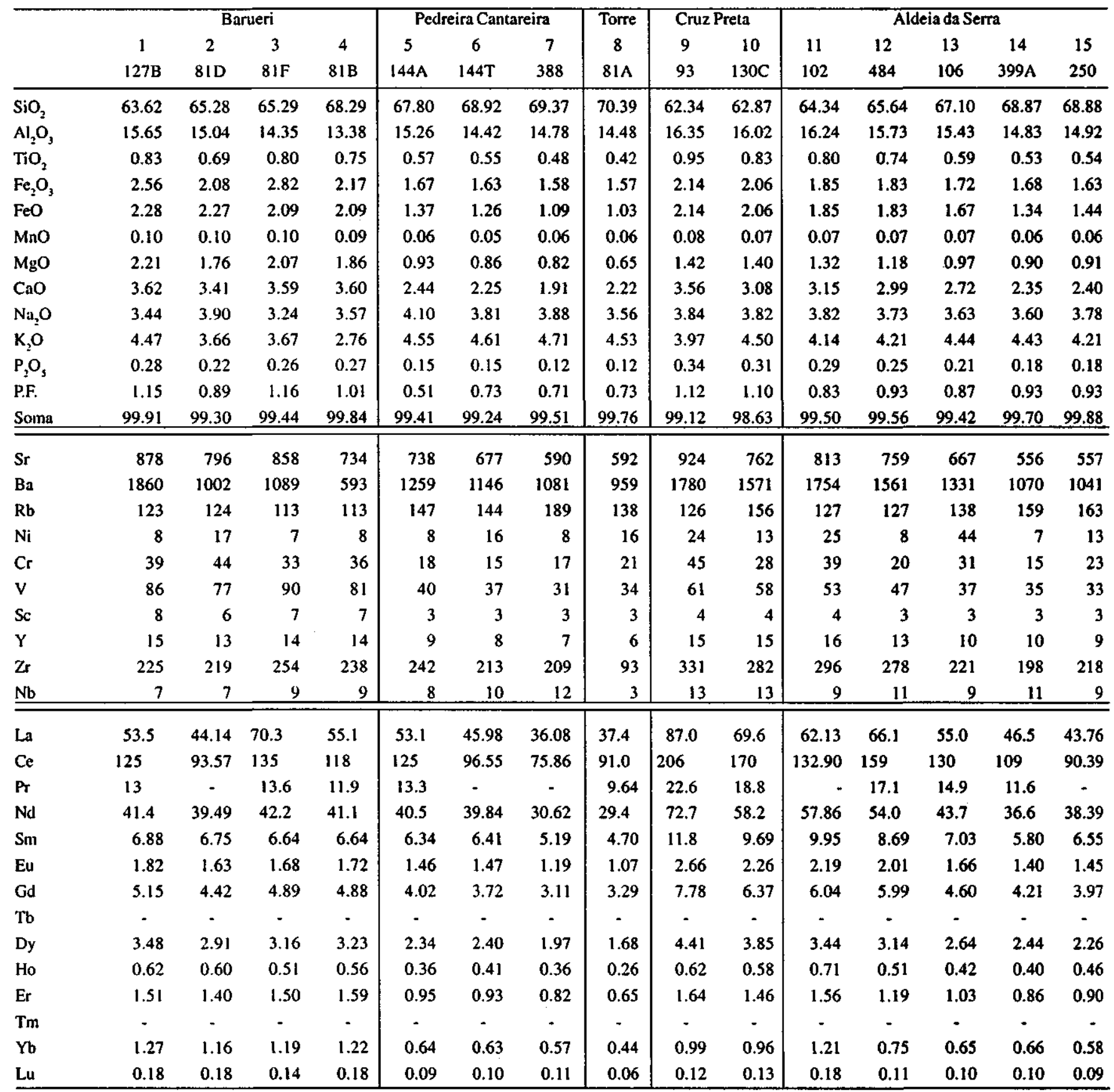


Tabela 2 - Elementos maiores, menores (em \% de peso), traços e ETR (em ppm) para 26 amostras do Complexo Itaqui (Cont.) Table 2- Major, minor (weight \%) and trace elements and REE (in ppm) for 26 samples of the Itaqui Complex (Cont.)

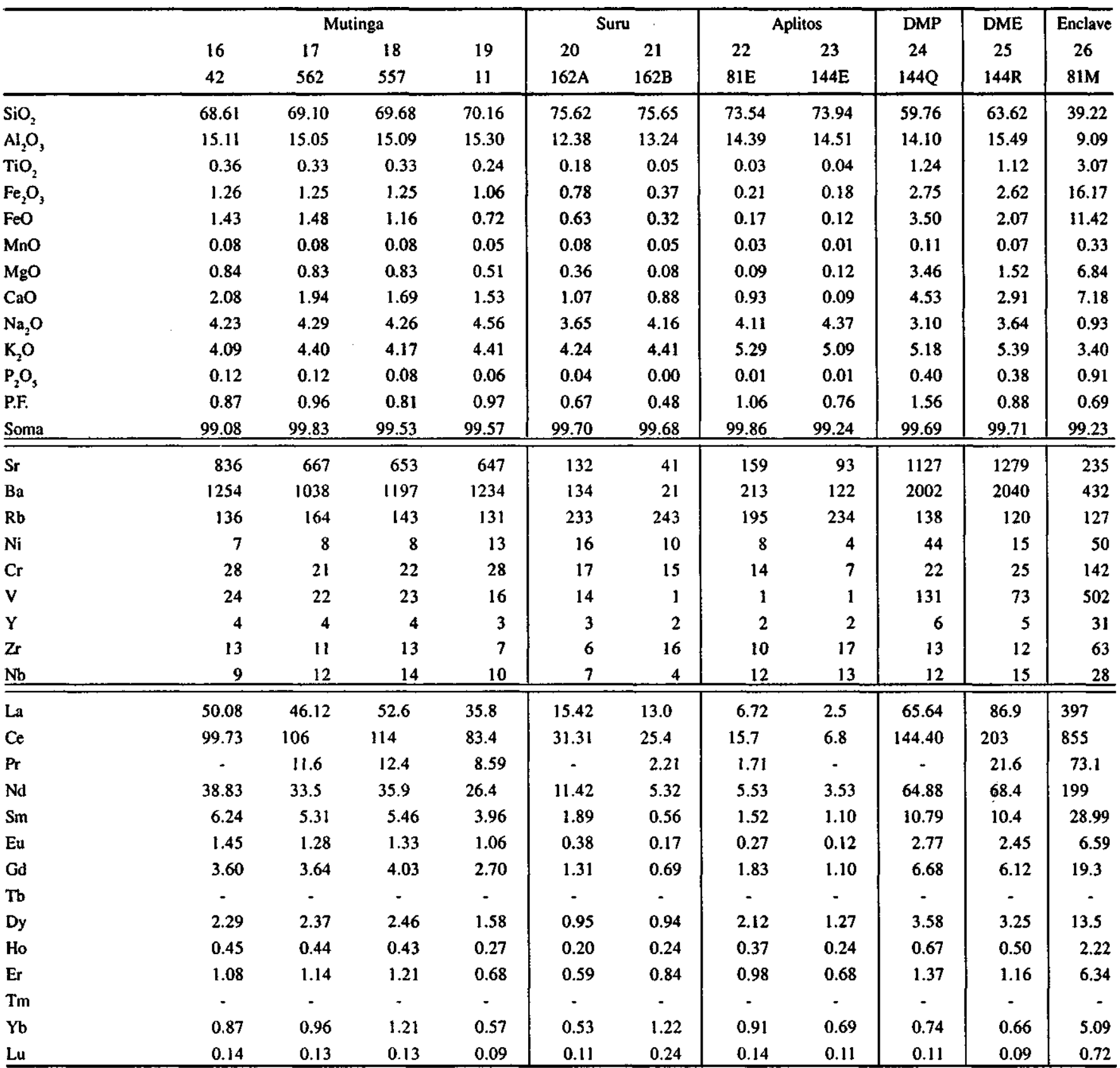

também pode ser dividido em dois subciclos: IIA (que inclui as unidades CP e AS) e IIB (que reúne as Unidades MU e $\mathrm{SU})$. O limite entre os subciclos tem por base os teores de $\mathrm{Na}_{2} \mathrm{O}$, maiores no subciclo IIB.

4. Os ciclos I e II caracterizam-se por uma variação temporal na sua composição dada por teores crescentes de sílica.

5. A associação 5, dada pelos turmalina-muscovita aplitos (APL), é uma manifestação magmática residual, independente e peraluminosa, cuja frequência diminui com o decréscimo da idade de colocação das unidades (os aplitos são mais frequentes na Unidade BA e ausentes nas Unidades MU e SU) (Ferreira 1991, Wernick \& Ferreira 1991).

6. Desta maneira, o Complexo Itaqui enquadra-se nos complexos cálcio-alcalinos tipo múltiplos e compostos no sentido de Pitcher (1985).
7. A unidade magmática inicial do ciclo II (Unidade Cruz Preta) é mais rica em Ti, $\mathrm{Zr}, \mathrm{P}$ e Y que a unidade magmática inicial do ciclo I (Unidade Barueri) (Figs. 4 e 6, Tabs. 2 e 3).

8. Em termos de ETR, a evolução magmática do ciclo I é distinta da do ciclo II. Enquanto o primeiro caracteriza-se por razões normalizadas $\mathrm{Ce} / \mathrm{Yb}$ e $\mathrm{La} / \mathrm{Lu}$ crescentes, no segundo estas razões apresentam valores progressivamente decrescentes (Fig. 5, Tab. 3). Este fato reflete-se também nas razões normalizadas $\mathrm{La} / \mathrm{Sm}$ e $\mathrm{Gd} / \mathrm{Lu}$ (Tab. 3, Fig. 5) e indica que no ciclo I as variações nos ETR são devidas a uma variacão preferencial em minerais acessórios enriquecidos em ETRP, e no ciclo II em minerais acessórios preferencialmente enriquecidos em ETRL (Fig. 5, Tab. 3). Esta afirmação fica patente na figura 6 , na qual linhas que unem os valores médios do ciclo IA e IB têm inclinação distinta das definidas pelas unidades magmáticas dos subciclos IIA e IIB. Assim, nos gráficos elementos traços versus ETRL e 
Tabela 3 - Composição média de alguns óxidos (\% em peso), elementos traços (ppm), elementos terras raras (valores normalizados por condrito) e razões entre elementos para as unidades ígneas do Complexo Itaqui. FÊMICOS representa a porcentagem dos minerais ferro-magnesianos normativos, e EC o enclave cognato na Unidade Barueri (BA). Símbolos como na fisura 1

Table 3 - Average data of some oxides (weight \%), trace elements (ppm) and rare-earth elements (chondrite normalized) and some element ratios for the igneous units of the Itaqui Complex. FÊMICOS means the percentage of normative Fe-Mg minerals, and EC a cognate enclave from the Barueri granodiorite. Symbols as in figure 1

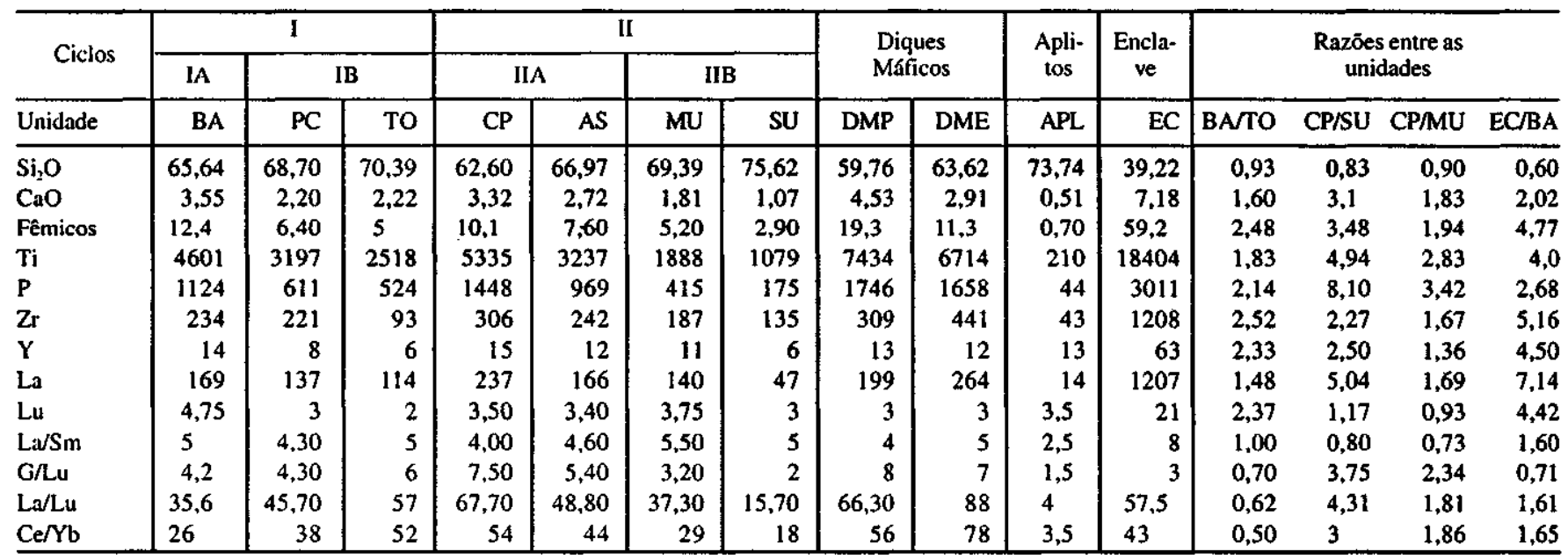

elementos traços versus Eu, as linhas evolutivas do ciclo I são sistematicamente mais inclinadas que as do ciclo II. Patente são as diferenças nos gráficos elementos traços versus ETRP, onde as variações nos dois ciclos são opostas. $\mathrm{O}$ reforço deste fato consta da tabela 3 , na qual se verifica que não só os valores médios absolutos de Ti, $\mathrm{Zr}$, P e Y são distintos para os dois ciclos, mas também que as suas variações relativas, dada pelas razões $\mathrm{BA} / \mathrm{TO}$ e $\mathrm{CP} / \mathrm{SU}$, são diferentes.

9. Todos os espectros de ETR das unidades magmáticas dos ciclos I e II apresentam a forma de um S suave, mais ou menos inclinado (dado pela razão $\mathrm{La} / \mathrm{Lu}$, Tab. 3), com exceção da Unidade Suru (que fecha o ciclo II), que apresenta pequena anomalia de Eu (Fig. 5).

10. Sob o aspecto dos elementos traços, verifica-se que a diferença geoqufmica entre as Unidades Barueri, Pedreira Cantareira e Torre do ciclo I é aproximadamente a mesma, o mesmo ocorrendo em relação às Unidades Cruz Preta, Aldeia da Serra e Mutinga do ciclo II. Já, a Unidade Suru apresenta um grau de diferença geoquímica bem maior, refletido não só pelos teores absolutos de $\mathrm{Zr}$, Ti, $\mathrm{P}$ e $\mathrm{Y}$, mas também pela comparação das razões BA/TO, CP/MU E CP/ SU (Tab. 3).

11. Os teores globais de ETR nos ciclos I e II decrescem com o aumento do teor em $\mathrm{SiO}_{2}$, e com a diminuição dos teores de $\mathrm{P}, \mathrm{Ti}, \mathrm{Zr}$ e Y e, conseqúentemente, também com a soma (Ti $+\mathrm{Zr}-\mathrm{f} \mathrm{P}+\mathrm{Y}$ ), aqui tomada como expressão do conteúdo de minerais acessórios portadores de ETR. Os teores também diminuem com a diminuição do índice de minerais fêmicos normativo (Fig. 4). Verifica-se, também, que, nos gráficos considerados, os alinhamentos das unidades magmáticas dos ciclos I e II são algo distintos como já ressaltado em relação à figura 6 .

12. O mesmo quadro observa-se também nas diferentes unidades, nas quais o total de ETR diminui sistematicamente com o aumento do teor de $\mathrm{SiO}_{2}$ (Tab. 2 e Fig. 2 de Wernick et al. 1992).

As principais constatações acima listadas indicam que, para os dois ciclos magmáticos, a variação no conteúdo de ETR é controlada essencialmente pelo fracionamento conjunto de minerais acessórios (allanita, titanita, apatita e zircão) e que a participação relativa destes minerais foi distinta, quer nos dois ciclos quer nos diferentes subciclos.

No ciclo I, o decréscimo dos ETRL, do Eu e dos ETRP foi contínuo, como atestam as retas nos gráficos $\mathrm{Ti}, \mathrm{Y}$ e $(\mathrm{Ti}+\mathrm{P}$ $+\mathrm{Zr}+\mathrm{Y})$ versus ETRL, Eu e ETRP da figura 6, o paralelismo dos padrões de ETR das Unidades BA, PC e TO (Fig. 5), assim como diversas razões da tabela 3.

A queda simultânea dos teores de Ti, P, Zr, e Y e do total de ETR com o aumento do teor em $\mathrm{SiO}_{2}$ (Tab. 2) indica a participação simultânea dos minerais acessórios titanita, apatita, zircão e allanita no fracionamento, e o aumento regular da relação La/Lu sugere o predomínio do zircão (mineral enriquecido em ETRP) na modelagem particular dos espectros de ETR das mencionadas unidades magmáticas do ciclo I. Entretanto, os gráficos $\mathrm{P}$ e $\mathrm{Zr}$ versus ETRL, Eu e ETRP (Fig. 6) sugerem que a importância da apatita e do zircão varia nos subciclos IA e IB.

Papel subordinado é desempenhado pela hornblenda apesar da relação hornblenda/biotita diminuir da Unidade BA para a Unidade PC e da hornblenda faltar na Unidade TO. Tal fato decorre do espectro grosseiramente suborizontal e da relação mineral/condrito desse mineral ser da ordem de $10^{1}-10^{2}$ (Gromet \& Silver 1983). Desta maneira, a influência da hornblenda só é detectável pela quebra do alinhamento dos valores das Unidades B A-PC-TO no gráfico soma de ETR versus índice Fêmico Normativo da figura 4.

$\mathrm{O}$ fracionamento do plagioclásio, indicado pelas relações $\mathrm{SiO}_{2}$ versus $\mathrm{CaO}$ da tabela 2 e pela figura 2 , não tem papel decisivo na modelagem dos espectros de ETR das Unidades BA, CP e TO, como indica a ausência, nestes, de anomalias negativas de Eu (Fig. 5).

No ciclo II, o total de ETR também diminui com a queda dos teores de $\mathrm{Ti}, \mathrm{P}, \mathrm{Zr}$ e $\mathrm{Y}$ e com o aumento do teor de $\mathrm{SiO}_{2}$ (Fig. 4 e Tab. 2), sugerindo a influência combinada de allanita, zircão, titanita e apatita na modelagem dos espectros de ETR das Unidades CP, AS e MU (Fig. 5). Entretanto, a figura 6 revela claramente que a participação relativa destes minerais foi sistematicamente distinta nos subciclos IIA e IIB. Não obstante, o regular decréscimo da relação La/ $\mathrm{Lu}$ em todo o ciclo II indica um papel dominante da allanita (mineral enriquecido em ETRL) na modelagem dos espectros de ETR. 


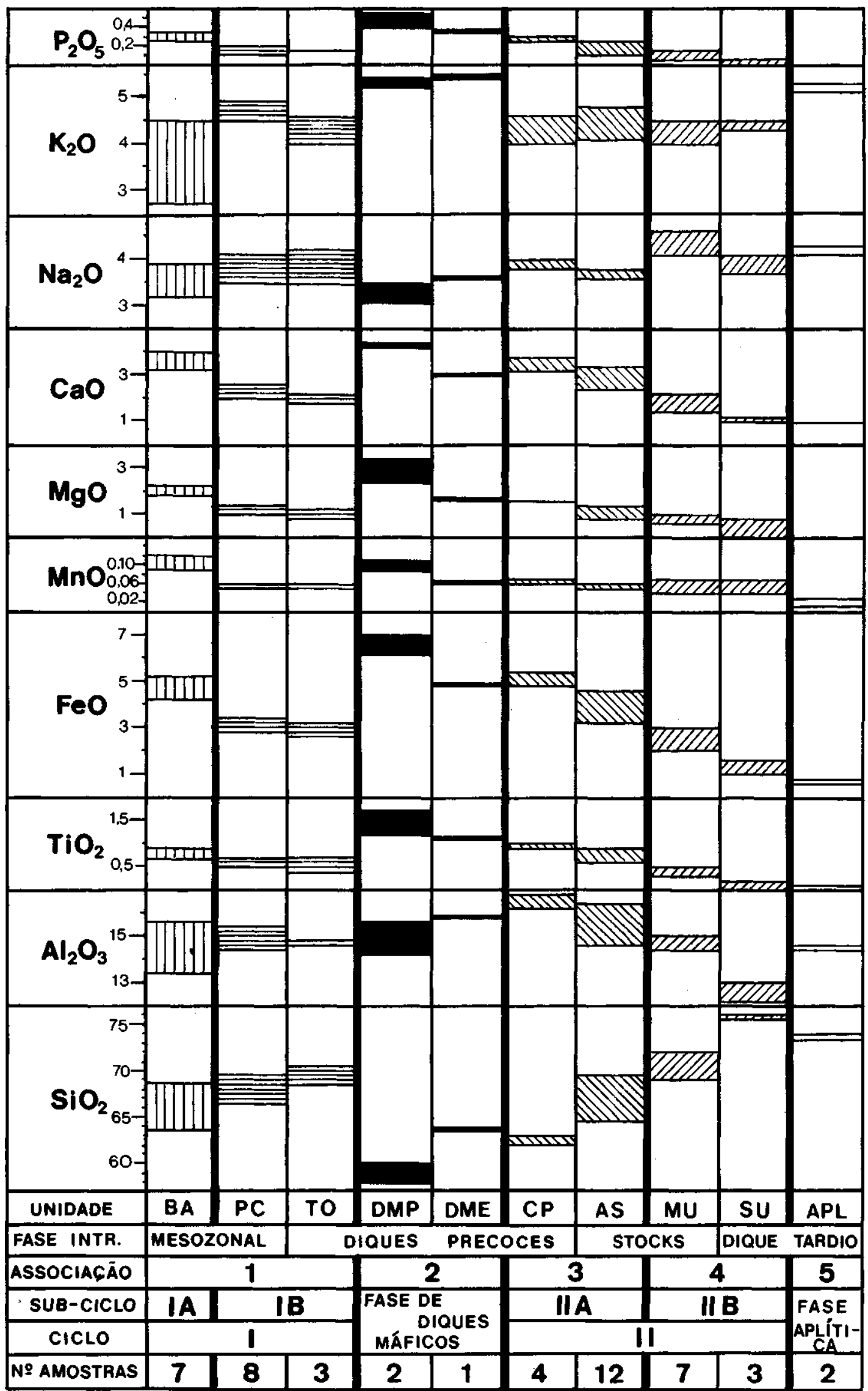

Figura 3 - Variação da composição química (em porcentagem de peso) das unidades ígneas do Complexo Granitóide Itaqui. Símbolos conforme afigura 1. Segundo Wernick et al. (1993)

Figure 3 - Compositional varialion (weight percent) of the igneous units of the Itaqui Complex. Symbols as in figure 1. After Wernick et al. (1993) 


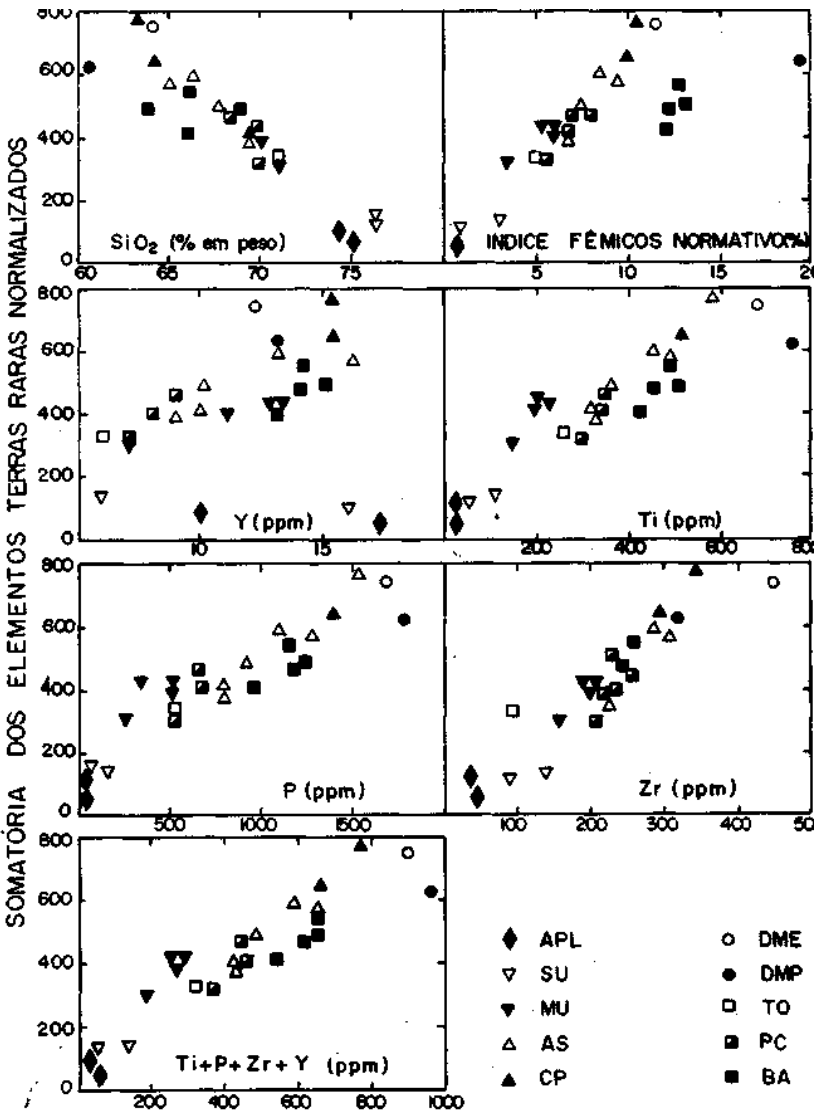

Figura 4 - Diagramas das somas dos elementos terras raras (excluidos $\mathrm{Pr}, \mathrm{Dy}$ e Tm) normalizados por condrito versus $\mathrm{SiO}_{2}$, indice defêmicos normativos, $\mathrm{Y}, \mathrm{Ti}, \mathrm{P}, \mathrm{Zr}$ e (Ti $+P+\mathrm{Zr}+Y$ ) para as diferentes unidades ígneas do Complexo Itaqui. Símbolos segundo afigura 1 Figure 4 - Diagrams of total rare-earth elements (except Pr, Dy and Tm) chondrite normalized against $\mathrm{SiO}_{2}$, normative femic minerais, $\mathrm{Y}, \mathrm{Ti}, \mathrm{P}, \mathrm{Zr}$ and $(\mathrm{Ti}+\mathrm{P}+\mathrm{Zr}+\mathrm{Y})$ for igneous units of Itaqui Complex. Symbols as in figure $\mathrm{l}$

O papel da biotita, único mineral fêmico das unidades do ciclo II, é negligenciável na modelagem dos espectros, não só por seu conteúdo relativamente baixo em algumas unidades, mas também por apresentar uma relação mineral/ condrito próximo a l (Gromet \& Silver 1983).

O papel do plagioclásio faz-se sentir apenas na Unidade SU dada por monzogranitos hololeucocráticos, através de pequena anomalia de Eu (Fig. 5).

A influência variável dos diferentes minerais acessórios na modelagem dos padrões de ETR dos ciclos I e II, com papel dominante do zircão no primeiro e da allanita no segundo, destoa dos valores de $\mathrm{Zr}, \mathrm{Ti}, \mathrm{P}$ e Y sistematicamente maiores da Unidade $\mathrm{CP}$ (início do ciclo II) em relação à Unidade BA (início do ciclo I), conforme as tabelas 2 e 3. Tal fato exige que o teor em ETR varie para uma mesma espécie mineral nos dois ciclos. Os seguintes dados petrográficos suportam esta hipótese:

A. os zircões do ciclo I são mais metamictizados que os do ciclo II (com excessão das Unidades CP e AS) e suas morfologias (controladas por elementos traços e ETR) variam nas diferentes unidades (Ferreira et al 1992); B. os halos pleocróicos em torno de allanitas inclusas em biotita variam nas diferentes unidades, assim como a coloração da allanita, sugerindo conteúdos variáveis em elementos radioativos neste mineral para as diferentes unidades magmáticas;

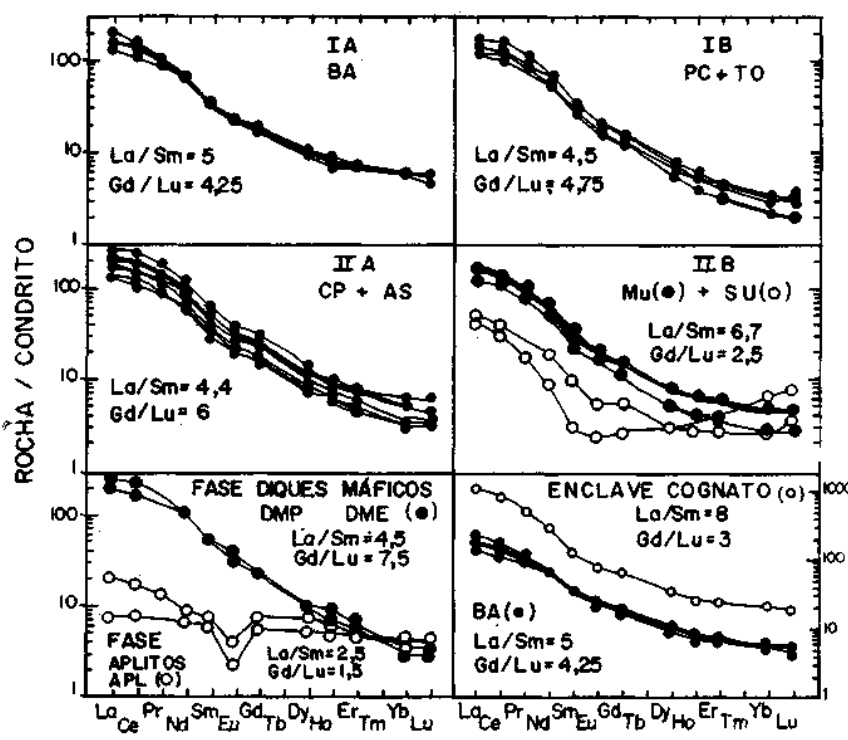

Figura 5 - Padrões de elementos terras raras normalizados por condrito para os subciclos magmáticos (IA, IB, IIA e IIB), diques máficos e aplíticos e para um enclave cognato do Granodiorito Barueri. Símbolos segundo a figura 1 Figure 5 - Chrondrite-normalized rare-earth element patterns for the magmatic subcycles (IA, IB, IIA and IIB), the mafic and aplitic dikes and a cognate enclave from the Barueri Granodiorite. Symbols as in figure 1

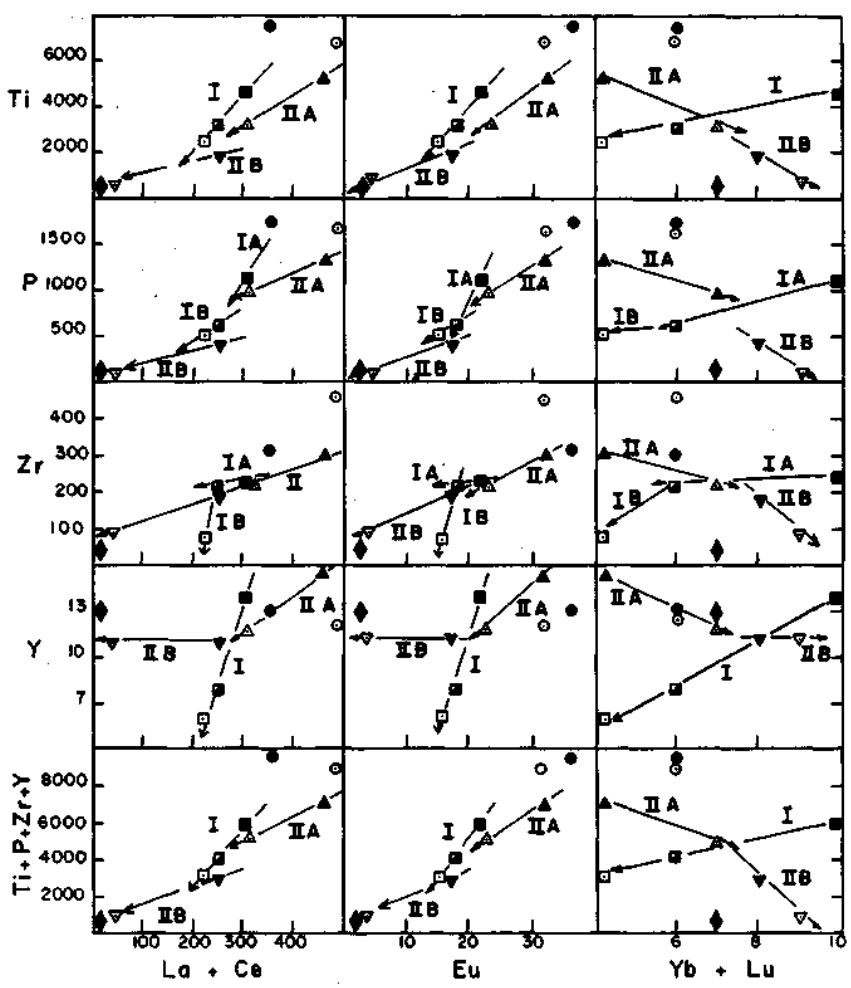

Figura 6 - Diagramas dos valores médios normalizados por condrito de elementos terras raras leves $(L a+C e), E u$ e elementos terras raras pesadas $(\mathrm{Yb}+\mathrm{Lu}$ ) versus $\mathrm{Ti}, \mathrm{P}, \mathrm{Zr}$, $Y e(T i+P+Z r+Y)$ (valores médios em ppm) para as diferentes unidades ígneas do Complexo Itaqui, Símbolos segundo afigura 1

Figure 6- Diagrams of average normalized of light REE $(\mathrm{La}+\mathrm{Ce})$, Eu and heavy $\operatorname{REE}(\mathrm{Yb}+\mathrm{Lu})$ data against Ti, $\mathrm{P}, \mathrm{Zr}$, Y and $(\mathrm{Ti}+\mathrm{P}+\mathrm{Zr} \mathrm{H}-\mathrm{Y})$ (mean values in $\mathrm{ppm}$ ) for the igneous units of the Itaqui Complex. Symbols as in figure 1 
C. a presença de grãos prismáticos hexagonais e anédricos arredondados de apatita varia nas diferentes unidades, assim como a relação entre apatitas eqüidimensionais e aciculares (Ferreira 1991, Ferreira \& Wernick 1991), sugerindo contribuições diferentes deste mineral no total de ETR da rocha (Ryerson \& Hess 1980).

O fracionamento de minerais acessórios, considerado aqui como fator primordial para a explicação da variação dos ETR no Complexo Itaqui, requer para seu funcionamento um magma original com viscosidade e yield strenght baixo, já que Shaw (1965), assumindo para magmas graníticos uma viscosidade newtoniana de $10^{\circ}$ poise e uma densidade de 2,3 gr $/ \mathrm{cm}^{3}$, mostrou que cristais de feldspato, biotita e hornblenda com $1 \mathrm{~mm}$ de diâmetro teriam uma decantação de menos de $1 \mathrm{~m} / \mathrm{ano}$, não considerado o yield strenght do magma.

Entretanto, as seguintes feições são indicativas da existência de uma viscosidade suficientemente baixa que pudesse permitir a operação de um dos vários processos de separação entre cristais e líquidos coexistentes:

I. A presença na Unidade Barueri de enclaves cognatos enriquecidos em minerais acessórios e máficos e, em consequência, extremamente enriquecidos em ETR (Tabs. 1, 2 e 3, Fig. 5). Estas características confirmam a concentração essencial dos ETR nos minerais acessórios e, de forma subordinada, na hornblenda.

Estes enclaves formaram-se antes que a viscosidade do magma se tornasse crítica para a preservação de estruturas de fluxo, já que exibem forma alongada paralela à isoorientação dos megacristais de microclina, observada com frequência na Unidade Barueri. Pela ação do fluxo magmático, alguns destes enclaves foram desmembrados originando schlieren difusas e esgarçadas; nas extremidades, o enclave chega a ser decomposto em conjuntos de coágulos de minerais máficos com dimensões milimétricas (Wilshire 1967, Smith 1975, Ferreira 1991, Wernick \& Ferreira 1991). A segregação de zircão, mineral enriquecido em alguns enclaves microgranulares, foi constatado em outros granitóides (Quinn 1943, Hall \& Eckelmann 1961, Karner \& Helgesen, 1970).

II. A frequente ocorrência de texturas em synneusis que, para a sua geração, exige uma viscosidade baixa para permitir a coalescência de minerais (Ferreira 1991, Ferreira \& Wernick 1991).

III. A preservação de estruturas turbilhonares desenhadas pelo arranjo dos megacristais nas unidades porfiróides do Complexo Itaqui. Tal fato indica que, antes de ser alcançada uma viscosidade crítica, os diferentes impulsos magmáticos exibiam elevada dinâmica, só possível em magmas com viscosidade relativamente baixa (Wernick \& Ferreira 1991).

IV. A ocorrência de margens de resfriamento junto ao contato de algumas unidades do Complexo Itaqui (Ferreira 1991, Wernick \& Ferreira 1991). Este fenômeno restringese essencialmente às unidades eqüigranulares e indica a colocação de magmas líquidos e quentes, como corroborado pela tipologia de zircão (Ferreira et al 1992).

V. Fenômenos de assimilação parcial de diques sinplutônicos por suas encaixantes (Wernick \& Ferreira 1987, Ferreira 1991). Nos diques máficos, despedaçados pelo fluxo magmático, os fragmentos são envolvidos e localmente digeridos por um conjunto de vênulas de granito leucocrático. Mobilidade, temperatura e taxa de voláteis elevadas do magma envolvente são pré-requisitos para estas assimilações. A alta mobilidade é relatada pela forma irregular, comprimento, pequena espessura e aspectos texturais das vênulas do magma invasor; sua alta temperatura é indicada pela tipologia de zircão e os elevados teores de voláteis pela presença de aplitos portadores de turmalina.

VI. Sinais de reação em condições de desequilíbrio, como o manteamento de cristais de quartzo por biotita (Ferreira 1991). Estas reações indicam uma viscosidade tal que per- mitiu a difusão de elementos químicos necessários para a geração da mencionada reação.

As nítidas diferenças entre os ciclos I e II - nos elementos maiores, menores, traços, ETR e nas características petrográfícas dos minerais acessórios, - não se coadunam com a hipótese de que todas as unidades do Complexo Itaqui seriam o resultado da mistura magmática entre dois membros de composição contrastante e fixa, ou que os diferentes subciclos representem a drenagem de um câmara magmática estratificada com variações químicas sistemáticas do topo para a base. Os dados apontam para a intrusão de impulsos magmáticos sucessivos provenientes de uma fonte magmática em contínua mudança genética e evolutiva, caracterizando assim um processo global extremamente complexo, atestado entre outras pelas relações $\mathrm{K}_{2} \mathrm{O} / \mathrm{Na}_{2} \mathrm{O}$ (Fig. 3). Dados petrográfícos indicam que em pelo menos uma das etapas deste processo (genética, de maturação ou de colocação) ocorreu processos de mistura magmática indicados pela coexistência de apatitas prismáticas eqüidimensionais e aciculares, synneusis, zoneamento inverso de plagioclásios, manteamento de grãos de quartzo por biotita etc. (Ferreira 1991, Ferreira \& Wernick 1991).

CONCLUSÕES 1. O Complexo Granitóide Itaqui é constituído por dois ciclos magmáticos (I e II), separados por uma fase de magmatismo mais básico e seguidos por uma fase magmática final, dada por aplitos portadores de turmalina e muscovita.

2. Cada ciclo é subdividido em dois subciclos (IA, IB, IIA e IIB) integrados, respectivamente por uma (BA), duas (PC e TO), duas (CP e AS) e duas (MU e SU) unidades magmáticas.

3. A unidade inicial do ciclo II é mais rica em Ti, $\mathrm{P}, \mathrm{Zr}$ e Y que a do ciclo I, e o ciclo II mostra-se mais diferenciado que o ciclo I.

4. Em ambos os ciclos, o conteúdo total de ETR diminui com o aumento dos teores de $\mathrm{SiO}_{2}$.

5. Os dois ciclos mostram variaçõ̃es distintas em relação aos ETR. Enquanto no ciclo I as relações $\mathrm{La} / \mathrm{Lu}$ (ou Ce/Yb) crescem continuamente com a sucessão das unidades magmáticas), no ciclo II ocorre o contrário.

6. As diferenças nas variações dos ETR são explicáveis, no ciclo I, por um fracionamento de minerais acessórios (zircão, apatita, titanita e allanita) e fêmicos (hornblenda), sendo o zircão o principal responsável pelo enriquecimento relativo do ciclo em ETRP. No ciclo II, a variação nos espectros de ETR também é devida ao fracionamento de uma combinação de zircão, allanita, titanita e zircão, cabendo um papel preponderante para a allanita no aumento relativo do ciclo em ETRL.

7. Numerosas feições geológicas e texturais observadas no Complexo Itaqui indicam uma viscosidade que permitiu a atuação do processo de fracionamento magmático. 8. Nenhum dos padrões de ETR das unidades dos dois ciclos mostra anomalia negativa de $\mathrm{Eu}$, com exceção da Unidade Suru, a mais jovem do subciclo IIB. Isto indica que a assinatura geoquímica, devido ao fracionamento de plagioclásio, só é ressaltada em rochas graníticas evoluídas, empobrecidas em minerais acessórios e máficos. 9. Os dados ora disponíveis indicam que o Complexo Itaqui é o resultado da acreção de numerosos impulsos magmáticos sucessivos provenientes de uma fonte em contínua mudança genética/evolutiva, configurando um processo complexo no qual ocorreu, em parte, fenômenos de mistura magmática. Sob este aspecto, o Complexo Itaqui é múltiplo e composto.

Agradecimentos O primeiro autor agradece ao $\mathrm{CNPq}$ o apoio dado ao presente trabalho por meio do processo $500459 / 90-8$, e o segundo autor à FAPESP ao auxílio concedido pelo processo $92 / 1333-5$. 


\section{REFERÊNCIAS BIBLIOGRÁFICAS}

AGUE, J.J. \& BRIMHALL, G.H. 1988. Magmatic are asymmetry and distribution of anomalous plutonic belts in the batholits of Califórnia: effects of assimilation, crustal thickness and depht of crystallization. Bull. Geol. Soc. Am., 100:912-927.

ARTUR, A.C.; EBERT, H.; WERNICK, E. 1991 Magmatismo e tectônica no Complexo Socorro (SP/MG). In: SIMP. REG. GEOL., 2. São Paulo, 1991. Atas... São Paulo, SBG. v. 1, p. 105-112.

ARZI, A.A. 1978. Critical phenomena in the rheology of partially melted rocks. Tectonophvsics, 44(1-4): 173-184.

BAILEY, R.A.; DALRYMPLE, G.B.; LANPHERE, M.A. 1976. Volcanism, structure and geocronology of Long Valley caldera. Mono County, California. J Geoph. Res., 81:725-744

BUDZINSKI, H. \& TISCHENDORF, G. 1989. Distribution of REE among minerals in the Hercynian post kinematic granites of WesterssgebirgeVogtland, GDR.Z. Geol. Wiss., 17(11):1019-1031.

CAMPBELL, I.H. \& TURNER, J.S. 1986. The influence of viscosity on fountains im magmachambers. J. Petrol., 27:1-30.

CASTRO, A.; MORENO-VENTAS, I.; ROSA, J.D. 1991. H-type (hybrid) granitoids: a proposed revision of the granite type classification and nomenclature. Eartli-Sci. Rev., 31:237-253.

CHAPPELL, B.W.; WHITE, A.J.R.; WYBORN, D. 1987. The importance of residual source material (restite) in granite petrogenesis.J. Petrol, 28:1111-1138.

FERREIRA, C.J. 1991. Geologia, Petrografia e Tipologia de Zincão da Suite Intrusiva Itaqui, Barueri (SP). Rio Claro. 253 p. (Dissertação de Mestrado, IGCE/UNESP).

FERREIRA, C.J. \& WERNICK, E. 1989. Granito Itaqui (SP): caracterizacão das fácies e relações temporais. In: SIMP. REG. GEOL., 1. Rio de Janeiro, 1989. Atas... Riode Janeiro, SBG. p. 171-172.

FERREIRA, C.J. \& WERNICK, E. 1991. Petrografia da Suíte Intrusiva Itaqui (SP). In: SIMP. REG. GEOL., 2. São Paulo, 1991. Atas... São Paulo, SBG. p. 121-130.

FERREIRA, C.J.; WERNICK, E.; HÕRMANN, P.K 1992. Evolução magmática e tipologia de zircão no Complexo Granitóide Itaqui, SP. In: CONGR. BRÁS. GEOL., 37. São Paulo, 1992. Boletim de Resumos Expandidos... São Paulo. SBG. v. 1, p. 330-331.

GROMET, L.P. \& SILVER, L.T. 1983. Rare earth element distribution among minerais in a granodiorite and their petrogenetic implications. Geochim. Cosmochim. Acta, 47:925-939.

HALL, B.A. \& ECKELMANN, F.D. 1961. Significance of variations in abundance of zircon and statistical parameters on zircon population in a granodiorite dike, Bradford, Rhode Island. Am. J. Sci., 259: 622-634

HASUI, Y. 1963. Sobre os granitos turmaliníferos de Perus, São Paulo (SP). Bol. Soc. Bras. Geol., 12:37-108.

HILDRETH, W. 1981.Gradient insilicic magma chambers: implication for lilhospheric magmatism.J. Geoph. Res.,86(B11):10153-10192.

HILDRETH, W.; CHRISTIANSEN. R.L.; O'NEIL, J.R. 1984. Catastrophic isotopic modification of rhyolitic magma at time of caldera subsidence, Yellowstone plateau volcanic field.7. Geoph. Res., 89:8339-8369.

JACKSON, M.P.A. \& TALBOT, C.J. 1989. Anatomyof mushroom-shaped diapir. J. Struct. Geol., 11(1/2):211-230.

KARNER, F.R \& HELGESEN, J.0.1970. Petrologic significance of zircon variation in theTunk Lake, Soulheastern Maine. J. Geol., 78:480-498

LEAKE, B.E. 1990. Granite magmas: their sources, initiation and consequences of emplacement. J. Geol. Soc., 317:579-589.

MARSH, B.D. 1988. Crystal capture, sorting and retention in eonvecting magmas. Bull. Geol. Soc. Am. 100:1720-1737.

MARSH, B.D. \& MAXEY, M.R. 1985. On the distribution and separation of crysials in eonvecting magmas. J. Volcanol. Geotherm. Res., 24:95-150.

MARTIN, D. \& NOKES. R. 1989. A fluid-dynamical study of crystal settlingin eonvecting magmas. J. Petrol., 30(6): 1471-1500.

MARTIN, D.;GRIFFITHS, R.W.; CAMPBELL, I.H. 1987. Compositional and thermal convection i n magma chambers. Contrib. Mineral. Petrol., 96:465-475

OXBURGH, E.R. \& McRAE, T. 1984. Physical constraints on magmas contamination in the continental crust: an example, the Adamellis complex. Philos. Trans. Roy. Soc. London, A310:457-472.

PITCHER, W.S. 1985. A multiple and composite batholith. In: PITCHER, W.S.; ATHERTON, M.P.; COBBINGS, E.J.; BECKINSALE, R.D ed Magmatism at a plate edge - The Peruvian batholith. p. 93-191. New York, Halshed PressAViley \& Sons. 328 p.

POLI, G.E. \&TOMMASINI, S. 1991. Model for the origin and significance of microgranular enclaves in calc-alkaline granitoids. J. Petrol., 32(3):657-686.
QUINN, A.W. 1943. Settling of heavy minerais in a granodiorite dike at Bradford, Rhode Island.Aw. Min., 28:272-281.

REID, J.B.; EVANS, O.C.; FATES, D.G. 1983. Magma mixing in granitic rocks of the central Sierra Nevada, Califórnia. Earth Planet. Sci. Lett., 66:243-261.

RYERSON, F.J. \& HESS, P.C. 1980. The role of $\mathrm{P}_{2} \mathrm{O}_{3}$ in silicate melts. Geochim. Cosmochim. Acta, 44:611-624.

SHAW, H.R. 1963. Obsidian-H,O viscosities at 1.000 and 2.000 barsin the temperature range 700 to $900^{\circ}$ C. J. Geoph. Res., 68:6337-6343.

SHAW, H.R. 1965. Comments on viscosity, crystal settling, and convection m granitic magmas. Am, J. Sci., 263:120-152.

SHAW, H.R. 1972. Viscosities of magmatic silicate liquids: an empirical method of prediction. Am. J. Sci., 272:870-893.

SMITH, T.E. 1975. Layered granitic rocks at Chebucto Head, Halifax County, Nova Scotia. Can. J. Earth Sci., 12:456-463.

SPARKS, R.S.J. 1978. The dynamics of bubble formation and growth im magmas: a review and analysis. J. Volcanol. Geotherm. Res., 3:1-37.

SPARKS, R.S.J. \& MARSHALL, L. 1986. Thermal and mechanical constraints on mixing between mafic and silicic magmas. J. Volcanol. Geotherm. Res., 29:99-124.

SPARKS, R.SJ.íHUPPERT, H.E.; TURNER, J.S. 1984. The fluid dynamic of evolving magma chambers. Philos. Trans. Royal Soc. London, A310:511-534.

SPERA, F.J.; YUEN, D.A.; KIRSCHVINK, S.J. 1982. Thermal boundary layer convection in silicic magma chambers: effect of temperaturedependent rheology and implication for thermogravitational chemical fractionation. J. Geoph. Res., 87:8755-8767.

TURNER, J.S. \& CAMPBELL, I.H. 1986. Convection and mixing in magma chambers. Earth-Sci. Rev., 23:255-352.

WALKER, D. \& DeLONG, S.E. 1982. Soret separation of mid-ocean ridge basalt magma. Contrib. Mineral. Petrol., 79:231-240.

WALL, V.J.; CLEMENS, J.D.; CLARKE, D.B. 1987. Models for granitoid evolution and source composition. J. Geol., 95:731-749.

WERNICK, E. 1983. Granitos na região da Grande São Paulo. In: SIMP. REG. GEOL., 4. São Paulo, 1983. Guia de Excursão... São Paulo, SBG. 21 p.

WERNICK, E \& FERREIRA, C J. 1987. Um expressivo dique sinintrusivo no Granito Itaqui, arredores de São Paulo. In: SIMP. REG. GEOL., 6. Rio Claro, 1987. Aias... São Paulo, SBG. v. 1, p. 135-148.

WERNICK, E. \& FERREIRA, C.J. 1991. Estrutura, arquitetura e evolução do Complexo Granitóide Itaqui, SP. In: SIMP. NAC. ESTUDOS TECTÔNICOS, 3. Rio Claro, 1991. Boletim de Resumos... Rio Claro, UNESP-SBG. p. 62-63.

WERNICK, E.; HỖRMANN, P.K.; FERREIRA, C.J. 1991. Processos de evolução magmática no Complexo Granitóide Itaqui, SP, Brasil. In: CONGR. BRÁS. GEOQ., 3, e CONGR. GEOQ. DOS PAÍSES DE LINGUA PORTUGUESA, 1. São Paulo, 1991.Boletim de Resumos. São Paulo, SBGq. p. $271-275$

WERNICK, E.; HÔRMANN, P.K.; FERREIRA, C.J. 1992. Viscosidade e evolução de magmas granitóides cálcio-alcalinos: uma abordagem através de ETR. In: CONGR. BRAS. GEOL., 37. São Paulo, 1992. Boletim de Resumos Expandidos. São Paulo, SBG. v. 1, p. 348-349.

WERNICK, E.; FERREIRA, C.J.; HÕRMANN, P.K. 1993. Evolução das unidades magmáticas do Complexo Granitóide Itaqui (Pré-Cambriano Superior), Estado de São Paulo, Brasil: aspectos geológicos, petrográficos e geoquímicos. In: SIMP. INTERN. DEL NEOPROTEROZOICO- CAMBRICO DE LA CUENCA DEL PLATA, 1. Uruguai, 1993. Boletim de Resumos Expandidos... Montevideo, Dinamige. $6 \mathrm{p}$.

WILSHIRE, H.G. 1967. Mineral layering in the Twin Lakes granodiorite. Colorado. In: Igneous and Metamorphic Geology - a Volume in Honour of Arie Poldervaart. USA, Geol. Soc. Am., p. 235-261. (Memoir 15).

ZORPI, M.J.; COULON, C.; ORSINI, J.B.; COCIRTA, C. 1989. Magma mingling, zoning and emplacement in calc-alkaline granitoid plutons. Tectonophysics, 157:315-329.
Manuscrito A769

Recebido em 30 de março de 1993

Revisã o do autor em 27 de abril de 1993

Revisão aceita em 10 de maio de 1993 